\title{
Desafios no processo de ensino e aprendizagem: Estudo sob a ótica docente de curso de graduação
}

\section{Challenges in the process of teaching and learning: Study in the faculty of perspective of a graduate course}

\author{
Ana Carla Silva Alexandre \\ Mestranda em Ciências da Saúde ,Departamento de Enfermagem, Instituto Federal de Educação, Ciência e Tecnologia - \\ campus Pesqueira, E-mail: anacarlasalexandre@ @otmail.com, Endereço: Instituto Federal de Educação, Ciência e \\ Tecnologia - campus Pesqueira. BR- 232, Prado, Pesqueira -Pernambuco. Contatos: (87) 9 9605-3062.

\section{Luana Mendes Amorim} \\ Enfermeira, Especialista em Saúde Pública, Universidade de Pernambuco- Campus Caruaru, Pernambuco, \\ Departamento de Enfermagem E-mail: luanamendespesqueira@gmail.com \\ Nadjane Santos De Paula Patriota \\ Enfermeira. Faculdade Vale do Ipojuca-FAVIP/DeVry. Caruaru. Pernambuco, Brasil E-mail: \\ nadjaneprisma@hotmail.com \\ Valquiria Farias Bezerra Barbosa \\ Doutora em Ciências Humanas pela UFSC, Departamento de Enfermagem, Instituto Federal de Educação, Ciência e \\ Tecnologia - campus Pesqueira, Pernambuco, E-mail: valquiriaenfermeira@yahoo.com.br

\section{Valdeilson Lima De Oliveira} \\ Mestrando em Bioética pela UMSA, Enfermeiro da Secretaria Especial de Saúde Indígena (SESAI), Departamento de \\ Enfermagem. Pesqueira, Pernambuco, E-mail: valdeilson-indio@ hotmail.com

\section{Amanda Haissa Barros Henriques} \\ Mestre em Enfermagem pelo Programa Associado de Pós-Graduação em Enfermagem UPE/UEPB, Enfermeira, \\ Docente, Departamento de Enfermagem, Departamento de Enfermagem, Instituto Federal de Educação, Ciência e \\ Tecnologia - campus Belo Jardim, Pernambuco, E-mail: amandahaissa@gmail.com
}

\begin{abstract}
Resumo: Objetivou-se identificar fatores que interferem no processo de ensinagem do docente em um curso de graduação de uma instituição privada. Trata-se de um estudo descritivo e exploratório, com abordagem qualitativa, que foi realizado numa Instituição de Ensino Superior, localizada na cidade de Caruaru-PE. O estudo pontuou fatores positivos que interferem na ensinagem como o aprimoramento e experiência profissional, bem como, percebeu-se a eficácia do processo de ensinagem através da participação discente e da articulação teoria-prática. Com relação às dificuldades, a falta de interesse dos discentes, a alta carga horária, a escassez de tempo para o aprimoramento profissional e as exigências do mercado de trabalho, foram elencadas pelos docentes como principais desafios. Para ocorrer mudanças necessárias na ensinagem contemporânea, faz-se necessário um maior esclarecimento das demandas docentes, seus desafios e dificuldades, bem como, um aperfeiçoamento contínuo deste profissional e uma reorganização nas estratégias de ensino.
\end{abstract}

Palavras-chave: Instituições. Avaliação educacional. Docentes de enfermagem

Abstract: This study aimed to identify factors that interfere with the educational teaching process in an undergraduate degree from a private institution. It is a descriptive and exploratory study with a qualitative approach, which was carried out in a higher education institution, located in Caruaru-PE. The study pointed out positive factors that interfere with teaching and learning as the improvement and professional experience as well, it was noticed the effectiveness of the teaching process through student participation and theory-practice articulation. Regarding the difficulties, the lack of interest of students, the high workload, shortage of time for professional development and the demands of the labor market, were listed by teachers as major challenges. Changes needed to occur in contemporary teaching and learning, it is necessary to further clarification of the demands teachers, their challenges and difficulties as well as a continuous improvement of this professional and a reorganization in teaching strategies.

Key words: Schools. Educational measurement . Faculty nursing 


\section{INTRODUÇÃO}

Os desafios contemporâneos do ensino e sua diversificação, reconfiguram o sistema de educação superior (CNE, 2010). Nas constantes discussões sobre a educação universitária trata-se sobre o aumento da demanda e da oferta de oportunidades educacionais e a necessidade de diversificação tendo em vista a gama de culturas, os novos objetivos da educação no século XXI, as mudanças nos perfis profissionais e formativos $\mathrm{e}$, sobretudo o advento da interdisciplinaridade e tecnologia (BACKES et al, 2013).

A graduação em enfermagem tem como centro de discussão, a formação de profissionais da área de saúde com ênfase na integralidade humana associada ao ensino e a prática que abranja as necessidades dos clientes, da população e a ampliação da saúde (SILVA; FREITAS, 2010). Recentemente se tem discutido a respeito das influências paradigmáticas da ciência sobre a profissionalidade e a prática pedagógica dos professores universitários, percebendo-se a necessidade de desenvolver o processo educacional com capacitações e aptidões envolvendo a instrução e prática, atenuando o pensamento simplista que permeia o ensino e formando profissionais com reflexões abrangentes no sentindo de avaliar, sistematizar e decidir sobre seus comportamentos frente à realidade em consonância com as evidências científicas e ensejados nas diretrizes curriculares (SALEH et al, 2015).

Os atuais confrontos sobre as reformas do ensino e as pressões pela melhoria dos indicadores da educação mostram o docente como profissional base para a mudança. Contudo na realidade escolar brasileira, principalmente no ensino superior visualiza-se o isolamento do docente com ações restritas a sala de aula, ratificando $o$ profissional focalizado estritamente na transmissão da teoria (JUSTO; BRITO, 2011). Além do mais, os professores que possuem vasta experiência e anos de estudo são caracterizados pelo desconhecimento científico ao processo de ensino-aprendizagem pelo qual são responsáveis (PIMENTA; ANASTASIOU, 2010).

A ensinagem, por sua vez, indica uma prática social complexa, realizada pelos sujeitos envolvidos tanto na ação de ensinar quanto na de aprender, em um processo contratual, de parceria determinada e consciente na construção do conhecimento, resultantes de ações na sala de aula e fora dela (PIMENTA; ANASTASIOU, 2010).

É importante a horizontalidade entre docentes e discentes no processo de ensino-aprendizagem, visto que o professor é um componente fundamental para futura prática profissional dos acadêmicos. Considerando a docência uma ação humana, ela também é histórica e cultural, ou seja, inebriada de significados que constituem os sujeitos (ARAÚJO; VIEIRA, 2013). A história de vida dos docentes, as influências familiares e sua trajetória como estudante, são fundamentais para a definição da docência com profissão, fatores estes que, na maioria das vezes, justificam a perseverança diante das inúmeras fragilidades do ser docente tais como o contexto cultural, possibilidade de dedicação e duplas jornadas (OLIVEIRA; GONZAGA, 2012).

Para se alcançar metodologias ativas de ensinagem é importante compreender os pressupostos com relação às críticas à formação dos profissionais de saúde com o intuito de melhor se adaptar à realidade (COTTA, et al; 2012). O entendimento da necessidade de se ampliarem os espaços de ensino-aprendizagem (integração ensino-serviço); a participação da comunidade no processo de formação; as abordagens integradoras com outras áreas do conhecimento (interdisciplinaridade), e a indissociabilidade do ensino, da pesquisa e da extensão são fatores fundamentais a serem vivenciados na práxis acadêmica (ARABSHAHI, et al; 2015).

Neste sentido, a temática da educação e suas particularidades torna-se bastante relevante para a atualidade educacional do profissional docente. Considerando o contexto do papel do educador como peça fundamental no processo de formação acadêmica, este estudo buscou identificar fatores que interferem no processo de ensino e aprendizagem do docente em um curso de graduação de uma instituição privada.

\section{MATERIAL E MÉTODOS}

Trata-se de um estudo de caráter descritivo e exploratório, com abordagem qualitativa, que foi realizado numa instituição de ensino superior, de esfera administrativa privada, localizada na cidade de CaruaruPE (MINAYO, 2011). A amostra foi composta por 20 docentes do curso de enfermagem, denominados de E1 a E20 e que foram enquadrados no estudo por atender aos seguintes critérios de inclusão: ser docente do curso de enfermagem da Instituição de Ensino Superior (IES) e ter assinado o Termo de Consentimento Livre Esclarecido (TCLE). Como caráter de exclusão da pesquisa, estavam os docentes que se encontrassem em licença médica e/ou licença maternidade, aviso prévio ou ter sido contratado após o período da coleta.

Após a aprovação da pesquisa pelo Comitê de Ética da Faculdade Vale do Ipojuca-Favip/DeVry, sob o protocolo 130/2012 e respeitando as exigências da Resolução 466/12 do Conselho Nacional de Saúde sobre pesquisas envolvendo seres humanos a amostra foi submetida à apreciação do TCLE, e, em seguida, deu-se as assinaturas de consentimento (CONSELHO NACIONAL DE SAÚDE, 2012). Posteriormente, foi disponibilizado aos sujeitos da pesquisa, no período de março a abril de 2013, o instrumento pré-elaborado pelas autoras e, anteriormente, validado por um projeto piloto. $\mathrm{O}$ instrumento foi constituído, principalmente, por questões socioeconômicas e educativas, com o intuito de caracterizar os sujeitos, e questões específicas pertinentes ao objetivo do estudo.

Os dados da pesquisa foram coletados fazendo-se uso de um gravador de voz digital, em que os depoimentos foram gravados mediante a anuência dos entrevistados, prosseguindo com a disponibilidade de cada sujeito, em local e horário que garantiram a privacidade dos mesmos. Ademais, ressalta-se que houve a utilização de um diário de campo, servindo de instrumento auxiliar.

Após a coleta de dados, houve a transcrição e leitura minuciosa do material empírico, o qual foi analisado por meio da técnica de Análise de Conteúdo (AC), proposta por Bardin. De acordo com a autora supracitada, a AC divide-se em quatro fases as quais são necessárias para analisar os dados: fase de organização; 
exploração ou codificação do material; categorização e tratamento; e interpretação dos resultados (BARDIN, 2009).

Assim, os dados obtidos nesta pesquisa foram organizados de forma a quantificar os dados do instrumento através da plataforma Microsoft Office Excel 2007 e analisar as respostas discursivas da dimensão pedagógica por meio da técnica de análise de conteúdo de Bardin.

\section{RESULTADOS E DISCUSSÃO}

A principal característica do ensino universitário deve ser a possibilidade do diálogo, pois nenhum projeto pedagógico possui garantia e conhecimento pleno (SILVA; FREITAS, 2010). A percepção sobre o conhecimento que o docente tem, reflete diretamente na sua prática pedagógica, sendo este considerado social, e as pessoas (discentes e docentes) são sujeitos e não objetos neste processo (FREIRE, 2010). Conhecer o perfil do docente é, portanto, um alicerce para o descobrimento de suas demandas. Para tanto, apresenta-se, a seguir, o perfil sócio demográfico dos docentes estudados nesta pesquisa, conforme mostra a Tabela 1.

Tabela 1 - Perfil sócio demográfico dos docentes do Curso de Graduação em Enfermagem, Caruaru, 2013.

\begin{tabular}{|c|c|c|}
\hline Dimensão Pessoal & $\mathbf{N}$ & $\%$ \\
\hline \multicolumn{3}{|l|}{ Faixa etária } \\
\hline Adultos jovens $(20-40)$ & 13 & 65,0 \\
\hline Adultos (41-59) & 7 & 35,0 \\
\hline \multicolumn{3}{|l|}{ Sexo } \\
\hline Feminino & 12 & 60,0 \\
\hline Masculino & 8 & 40,0 \\
\hline \multicolumn{3}{|l|}{ Estado Civil } \\
\hline Solteiro & 5 & 25,0 \\
\hline Casado & 13 & 65,0 \\
\hline Divorciado & 2 & 10,0 \\
\hline \multicolumn{3}{|l|}{ Procedência em Caruaru } \\
\hline Sim & 11 & 55,0 \\
\hline Não & 9 & 45,0 \\
\hline \multicolumn{3}{|l|}{ Profissão } \\
\hline Professor & 4 & 20,0 \\
\hline Enfermeiro & 7 & 35,0 \\
\hline Professor e Enfermeiro & 5 & 25,0 \\
\hline Professor e outros & 3 & 15,0 \\
\hline Outros & 1 & 5,0 \\
\hline \multicolumn{3}{|l|}{ Atuação Profissional } \\
\hline Hospital/Ensino & 10 & 50,0 \\
\hline Outros/Ensino & 4 & 20,0 \\
\hline Ensino & 6 & 30,0 \\
\hline \multicolumn{3}{|l|}{ Turnos de Trabalho } \\
\hline Manhã e Noite & 2 & 10,0 \\
\hline Tarde e Noite & 2 & 10,0 \\
\hline Manhã, Tarde e Noite & 15 & 75,0 \\
\hline Noite & 1 & 5,0 \\
\hline \multicolumn{3}{|l|}{ Carga Horária total de Trabalho } \\
\hline Até $20 \mathrm{~h}$ & 2 & 10,0 \\
\hline Até $30 \mathrm{~h}$ & 5 & 25,0 \\
\hline Até $40 \mathrm{~h}$ & 2 & 10,0 \\
\hline Mais de $40 \mathrm{~h}$ & 11 & 55,0 \\
\hline \multicolumn{3}{|l|}{ Titulação } \\
\hline Especialista & 5 & 25,0 \\
\hline Mestre & 10 & 50,0 \\
\hline Doutor & 5 & 25,0 \\
\hline \multicolumn{3}{|l|}{ Anos de Docência } \\
\hline$>10$ & 6 & 30,0 \\
\hline Entre 5 e 10 & 9 & 45,0 \\
\hline$<5$ & 5 & 25,0 \\
\hline
\end{tabular}

Fonte: Pesquisa Direta (2013)

Os sujeitos do estudo constituíram um grupo majoritariamente de adultos jovens (20-40 anos) (65\%), feminino $(60 \%)$, casado $(65 \%)$ e com procedência em Caruaru-PE (55\%). Tal fato vai ao encontro do processo de feminização que acontece no Brasil e no Mundo atualmente. O termo feminização no mercado de trabalho se refere, normalmente, a um franco crescimento da população feminina em algumas profissões que historicamente eram desempenhadas pelos homens, como exemplo da medicina e odontologia (COSTA; DURÃES; 
ABREU, 2010), levando em consideração também o fato de a enfermagem ser predominantemente feminina de acordo com aspectos históricos e culturais da profissão.

Os dados no Brasil revelam que as mulheres constituem a maior parte dos estudantes de nível superior. Em vários cursos universitários, as mulheres já ocupam metade das vagas oferecidas (COSTA; DURÃES; ABREU, 2010). Segundo as autoras, a tendência deste processo de feminização foi verificada no Censo de 2000, mostrando que entre os profissionais com diploma universitário, 61,7\% eram mulheres, representando 95,3\% dos nutricionistas, $90,4 \%$ dos enfermeiros, 50,9\% dos cirurgiões-dentistas e 35,9\% dos médicos.

$\mathrm{O}$ dado que sinaliza a maior parte dos docentes residindo em Caruaru-PE, cidade onde se encontra a IES, nos remete a uma possível predisposição e possibilidade destes professores se engajarem em outras atividades que vão além da sala de aula e ensino, como por exemplo, na extensão e na pesquisa, uma vez que a universidade se sustenta em três pilares - ensino, pesquisa e extensão que cada vez mais necessitam estar inter-relacionados.

$\mathrm{O}$ ensino consiste no processo pedagógico em que a universidade e o corpo docente assistem o estudante quanto ao conteúdo literário, ou seja, mostram conceitos preestabelecidos por pesquisadores, formando alicerces para o desenvolvimento intelectual (ALBUQUERQUE et al., 2012).

A formatação complementar pela extensão e pesquisa propicia melhor aplicação dos conhecimentos adquiridos durante o ensino teórico. Um ponto forte da extensão universitária é que há o surgimento de um movimento no qual a pesquisa obtém novos resultados que são difundidos através do ensino e disseminados pela extensão. Portanto, torna-se evidente a importância da indissociabilidade do tripé formado por essas três principais funções (ensino, pesquisa e extensão) da universidade (MENDES et al., 2010).

De acordo com a Tabela 1, quando se questionou sobre a ocupação dos Docentes, é nítido que a maior parte dos entrevistados diz respeito a Enfermeiros (35\%), muitas vezes que acompanham apenas os alunos em atividades práticas de estágio, e Enfermeiros que também são professores de disciplinas teóricas ao longo do curso (25\%). E dentre as opções de atuação profissional, 50\% dos participantes do estudo estão correlacionados ao Hospital e Ensino, com a grande maioria trabalhando os três turnos $(75 \%)$ e com mais de 40 horas semanais de trabalho $(55 \%)$.

A acumulação de cargos é algo bem comum no cotidiano de profissionais de enfermagem para atingir um nível salarial digno e equiparado. No entanto, inúmeros são os efeitos negativos dessa carga horária redobrada e muitas vezes triplamente exercida, como por exemplo, a fadiga, a sobrecarga de trabalho e funções, a qualidade da assistência reduzida, entre outros fatores, uma vez que no desempenho de seu trabalho, esses profissionais enfrentam rotineiramente conflitos, sentimentos de ansiedade e impotência relacionadas com a forma como os serviços estão organizados e suas relações pessoais, perpassando por situações de vida e saúde de seus pacientes até uma sobrecarga de trabalho e precariedade da estrutura física para a realização de suas tarefas (TEIXEIRA; SILVA; MEDEIROS, 2010).
Estes autores ainda complementam que a prática que tanto enfermeiros, quanto professores desenvolvem está relacionada com o cuidado e a formação de outras pessoas, o que exige um planejamento regido por normas, regras e metodologias definidas a partir das necessidades dos clientes e, também, dos interesses administrativos institucionais. É uma prática que mobiliza além do manejo de técnicas padronizadas para a manutenção da saúde e a educação formal dos sujeitos, emoções e afetos que interferem na motivação e satisfação dos profissionais com seu trabalho.

Quanto à titulação, um percentual de $50 \%$ dos docentes eram Mestres e 45\% tinham entre 5 e 10 anos de experiência na docência, o que efetivamente pode contribuir para um ensino de qualidade e mostra maior capacidade e aptidão dos professores para lecionar.

Tais achados corroboram com o estudo de Lemos e Passos (2012) ao associar uma maior titulação e mais tempo na docência a um ensino sólido e de qualidade, umas vez que proporciona ao professor se dedicar mais à docência, obtendo e compartilhando experiências, perpetuando o conhecimento de forma saudável $\mathrm{e}$ aprimorando seu saber. $\mathrm{O}$ fato de conviver com o discente promove renovação e satisfação no desempenho do trabalho docente, de modo que ao se aproximar da realidade do aluno, o professor compreende melhor suas dúvidas, transmite o conhecimento de forma clara e contribui para o aprendizado de forma interessante e interativa.

É imprescindível promover a discussão em novos caminhos para uma educação mais ampla e moderna. $\mathrm{O}$ profissional em sua formação depende da qualidade técnica e interação pessoal, para a execução de um bom trabalho. E, esse processo necessita oferecer subsídios para o egresso desenvolver e aplicar suas práticas no âmbito profissional (ARAÚJO; VIEIRA, 2013; ).

Durante a graduação, o professor possui o papel fundamental não apenas no processo de ensino aprendizagem de temas técnicos, como também na formação ética do caráter que será projetado nas atitudes do futuro profissional. Assim deve-se focalizar um ensino reflexivo, a fim de desafiar, estimular e ajudar os alunos na construção de habilidades e competências que fortaleçam o compromisso profissional (MOURA; MESQUITA, 2010).

Em seguida, menciona-se a análise dos discursos dos componentes da amostra que foram agrupados em seis categorias, são elas: Interferências no ensino e aprendizagem; Eficácia na ensinagem; Desafio do ser docente; Dificuldades docentes; Elementos potencializadores e Projeto Político Pedagógico. A discussão, baseada na literatura científica atual, tenta compreender o contexto existente nas respostas dos docentes, as quais foram ricas de significado e relevância para alcançar os objetivos deste estudo.

\section{Interferências no ensino e aprendizagem}

Analisando a dimensão pedagógica do instrumento da pesquisa, os entrevistados expressaram fatores de interferência no seu processo de ensinagem. Assim, observou-se que com relação à interferência positiva, a maioria dos docentes entrevistados concorda que o aprimoramento profissional é elemento significativo 
para a eficácia do ensino. A formação pedagógica do docente universitário constitui-se num processo de extrema importância, pois, através dela, o profissional se aprimora para o exercício do magistério (OLIVEIRA; GONZAGA, 2012). Diante desta contemporaneidade da academia universitária, a formação do professor desse nível de ensino vem sendo bastante debatida, principalmente quando diz respeito ás atividades vinculadas ao trabalho docente onde é fundamental ter em mente o desenvolvimento profissional (BOLZAN; ISAIA; MACIEL, 2013).

Quando questionados sobre a interferência negativa, a falta de interesse discente foi a mais citada, nos recortes discursivos:

\begin{abstract}
"Gosto muito da docência, mas sou desmotivado pela falta de interesse do discente" (E14).

"A educação é uma via de mão dupla: eu preciso estar preparado e o aluno precisa querer aprender. Muitas vezes me sinto desmotivada quando percebo que ele não quer nada com a vida" (E10).

"Quando me deparo com aluno despreparado, que só que brincar e não quer saber de estudar, não sinto vontade de entrar na sala de aula" (E6).
\end{abstract}

A aprendizagem em uma sala de aula depende de um ambiente facilitador, em que o professor deve assumir atitudes frente aos seus alunos durante a realização de suas práticas docentes. $\mathrm{O}$ professor e o aluno devem manter uma relação de respeito mútuo, onde cabe ao docente, basicamente, dar ao aluno condições favoráveis para desenvolver seu potencial intelectual e afetivo (ARAÚJO; VIEIRA, 2013; ARABSHAHI et al, 2015). Além disso, os docentes são vistos como sujeitos responsáveis pela percepção do conhecimento do discente. É preciso que este educador, como agente transformador, incentive e estimule os discentes à construção do conhecimento (FREIRE, 2010). Para tanto, percebe-se nos relatos citados uma culpabilidade do docente para com o discente, favorecendo sua desmotivação.

De acordo com a relação que o professor mantém com o conhecimento, sua prática contribui ou não para a manutenção do status quo. Quando se pensa numa prática que busca transformação da sociedade, o professor assume o dever de contestar a ordem estabelecida, no sentido de aproximar, cada vez mais, o aluno, juntamente com o professor, da intimidade, da complexidade da teia de relações, da razão de ser do objeto em estudo (FREITAS; CARVALHO; OLIVEIRA, 2012). No entanto, ocorre uma verticalidade na relação aluno-professor, pois este se coloca como superior ao aluno por possuir um conhecimento teórico pregresso, prejudicando a formação crítico-reflexiva no processo de ensino-aprendizagem.

Quando o docente faz opção pela metodologia transformadora, este torna-se responsável por trabalhar favoravelmente tanto para que os sujeitos sejam bemsucedidos na estrutura, como para perceberem as ideologias introduzidas nas expectativas e as contradições nela existente. Nessa perspectiva, a tarefa do professor nas escolas e instituições de Ensino Superior é a de discutir o próprio processo da educação, o que passa por incentivar a curiosidade e o rigor dos alunos, não garantindo, mas permitindo que estes percebam as contradições existentes na sociedade, possibilitando, com isso, que alguns continuem de maneira mais comprometida nesse processo de transformação (FREIRE, 2010).

\section{Eficácia na ensinagem}

Na totalidade dos docentes estudados é percebida a eficácia do processo de ensinagem através da participação do discente. A formação da aprendizagem se dá a partir da composição de trocas de saberes que possibilitem haver o compartilhamento de ideias sobre o conhecimento com experiências e atividades conjuntas onde é possível evidenciar a dimensão da prática pedagógica e o conhecimento científico na construção de profissionais de enfermagem (BOLZAN; ISAIA; MACIEL, 2013; ROCHA, et al., 2015).

\section{“[...] Ensino existe em função de aprendizagem. Só há ensino efetivo se houver aprendizagem. A função primordial do docente é a de desenvolver estratégias para o alcance daquela aprendizagem" (E20; E18; E14; E10). \\ "[...]O processo Ensino - Aprendizagem depende de vários fatores, e um deles é a interação do professor e aluno" (E12). \\ "[...]Se percebo que o aluno está envolvido e consegue entender, é porque o processo está sendo eficaz (E3).}

A habilidade de manter os alunos envolvidos, participativos, discutindo coletivamente, e o uso refinado de estratégias de ensino adaptadas de acordo com a necessidade conjuntural, expressa e percebida pelo professor no espaço de ensino, caracterizam a prática docente (BACKES et al, 2013). Os professores que possuem esta capacidade, geralmente são docentes experimentados, que já acumulam uma trajetória, e por suas habilidades e saberes possuem maior condição de proporcionar aos seus alunos um ensino satisfatório sob o ponto de vista de conteúdo, de empatia e de relevância profissional assim como tem maior condição de fazer com que se atinjam os êxitos formativos pactuados socialmente, aspecto este de particular interesse no contexto de mudanças paradigmáticas na formação (BACKES; MOYA; PRADO, 2011).

$\mathrm{O}$ processo ensino-aprendizagem na formação acadêmica necessita fornecer aos discentes condições de práticas educacionais que os favoreçam a atuarem na concretização das transformações curriculares propiciando um movimento de ensinagem eficaz e de constante compreensão, capacitando-os a ingressarem no mercado de trabalho com pensamentos para uma educação inovadora que possibilite ao sujeito uma visão criticoreflexiva (SALEH et al, 2015).

.É fundamental que docentes e discentes se percebam em uma posição semelhante no contexto formador, onde seus objetivos devem estar voltados à inserção de profissionais no mercado com características reflexivas e com qualidades técnicas. Assim, o discente, na qualidade de aprendiz, e o docente, como facilitador 
dessa aprendizagem devem trabalhar em equipe, compartilhando e expressando ideias, buscando informações e utilizando disposições específicas no desempenhar de suas habilidades (PAZ; KAISER, 2011).

\section{Desafio do ser docente}

$\mathrm{O}$ processo de ensino-aprendizagem possibilita a construção de habilidades científicas durante o processo de formação, e a postura do professor no cumprimento de sua profissão contribuirá tanto para si quanto para seu alunado na formação do senso crítico, reflexivo e científico, elementos imprescindíveis na construção da cidadania. Logo, o papel do educador muda de foco e se dirige para a produção de conhecimentos e a construção da sua autonomia profissional (OLIVEIRA; GONZAGA, 2012).

Nos resultados de análise com os docentes, em relação à variável 'desafios na docência', a amostra considera como principal desafio da profissão, lidar com a falta de compromisso do alunado:

"A lógica do mercado chegou na academia. Alunos buscam diploma e não uma formação de fato acadêmica" (E19; E10; E9; E3).

"O baixo interesse discente desestimula o docente" (E4).

"Para ser docente nos dias atuais, é necessário o enfrentamento de alunos descompromissados, e muitas vezes não dispomos de mecanismos para fazê-los interagir" (E1).

O fundamental na aprendizagem de qualquer conteúdo é a construção das responsabilidades e da liberdade que se assume, mas não se deve separar o ensino dos conteúdos da formação ética (FREIRE, 2010; ROCHA, et al.,2015).

A contemporaneidade exige do docente, cada vez mais, sabedoria e criatividade para lidar com as adversidades modernas que imprimem em determinados discentes características negativas ao desenvolvimento do ensino. Atualmente se exige a formação de profissionais com perfil crítico-reflexivo e capazes de trabalhar em equipes. Esta necessidade requer novas metodologias de ensino-aprendizagem, tendo na problematização um instrumento de transformação (COTTA et al., 2012) .

Quando o professor foi indagado quanto às propostas para superação deste desafio, obtivemos as seguintes afirmativas:

\footnotetext{
"O professor tem que se automotivar, assim como motivar o aluno. Desafio factível" (E18; E14).

"É necessário usar de criatividade, para mantê-los motivados, dinâmicos, interessados" (E17).

"É imprescindivel lançar mão de ferramentas didáticas motivadoras, a fim de proporcionar interesse pelo campo da ciência. No entanto, quando pensamos no excesso de carga horária, fica complicado trabalhar nessa perspectiva” (E16)
}

Mesmo diante das dificuldades observadas na profissão de docente nos dias atuais é imprescindível que este se disponha a constante ajuste e mediação, considerando que esta profissão é composta por um conjunto de fatores interligados. O docente está lidando constantemente com situações diversas de emoção fazendo-se necessário a tomada de decisões, análise dos fatos e resolutividade de problemas, havendo assim possibilidades de entendimento no que diz respeito às nuances da aprendizagem (MOURA; MESQUITA, 2010).

\section{Dificuldades docentes}

A carreira docente é marcada por sentimentos de incertezas, dificuldades e medos experimentados durante o percurso. E essa problemática aumenta , quando estes são responsáveis pela condução de uma experiência alternativa na formação de estudantes, desde o planejamento, do domínio e da execução das atividades acadêmicas (COTTA et al., 2012).

Em seus discursos, os docentes expressam que dentre as maiores dificuldades em sua atuação no processo de ensinagem está relacionada à escassez de tempo. A jornada excessiva torna-se um grande empecilho para atualização e preparação de aulas mais criativas, atraentes e de qualidade. É o que revela as afirmações seguintes:

"Sem dúvida o principal problema é o
tempo" (E11).
"A administração do tempo conforme o
quantitativo de atividades é para mim a
maior dificuldade" (E18).
"A carga horaria alta tem determinado um
menor tempo de descanso para esta pleno
na atividade" (E5).
"Ausentar-se da IES para atualização é
uma dificuldade" (E4).

As exigências do competitivo mercado de trabalho requerem o aprimoramento profissional através da implantação de modelos de formação e gestão de trabalho por competências profissionais, neste contexto a importância de ampliar a qualificação dos trabalhadores de saúde nas dimensões técnica especializada, éticopolítica, comunicacional e de inter-relações pessoais para a participação como sujeitos integrais no mundo do trabalho é o grande desafio para a ocupação de espaços no mercado (JUSTO; BRITO, 2011; BACKES et al, 2013 ).

É fator fundamentalmente importante que instituições organizacionais que se submetem a concretização de metodologias, possam incentivar nos alunos seu lado de reflexão, não avaliando apenas a importância de seus resultados e recursos tecnológicos, mas que, sobretudo, professores sejam capacitados a trabalhar com essa mesma metodologia em frutuosa interdisciplinaridade, preocupando-se com o aprendizado do aluno (COTTA et al, 2012; PIMENTA; ANASTASIOU, 2010).

\section{Elementos potencializadores}

A partir das variáveis expostas como elementos pedagógicos que potencializam a atuação do docente em sala de aula os entrevistados pontuam a articulação 
teórico-prática como principal método que opera a favor da ensinagem, como observa-se nos discursos abaixo:

\section{"Promover o envolvimento dos discentes com a temática abordada e possibilitar a compreensão de como esse tema insere-se no contexto social, econômico e cultural que circunscreve o indivíduo" (E7). \\ "Professor capacitado e atualizado consegue trazer para a sala de aula elementos que potencializam o processo de ensino- aprendizagem" (E9)}

A articulação entre teoria e prática para a docência é fundamental na construção de saberes que orientam atuações de outras duas práticas sociais: a educação e docência universitária que devem ser entendidas, portanto, como uma prática social interdisciplinar que favoreça a discussão da reordenação do mercado de trabalho (SOUTO; BATISTA; ALVES, 2014). Percebe-se no relato dos professores que a eficácia do processo de ensinagem se dá através da participação discente, tomando por base a articulação teórico-prática, elemento potencializador de fundamental importância para o desenvolvimento desse processo de construção acadêmica.

O professor tem um grande leque de opções metodológicas, de possibilidades de organizar sua comunicação com os alunos, introduzir um tema, trabalhar com os discentes presenciais e virtualmente, além de avaliá-los. Cada docente pode encontrar sua forma mais adequada de integrar as várias tecnologias e procedimentos metodológicos por meio de um planejamento pedagógico sistemático e materializado em um plano de ensino esclarecedor (MOURA; MESQUITA, 2010).

\section{Projeto Político Pedagógico}

A proposta das novas Diretrizes Curriculares Nacionais, se bem direcionadas, podem proporcionar uma formação reflexiva, crítica e com maior capacidade de resolução dos problemas. Cabe ao professor, garantir que esse conjunto de competências acrescente no alunado a capacidade de desenvolvimento intelectual e profissional autônomo e permanente (CNE, 2010).

No que concerne ao Projeto Político Pedagógico (PPP), a maioria dos docentes de afirmam ter acesso e manuseio com este. No entanto, quando questionados sobre a utilização das ferramentas oferecidas por tal projeto no processo de ensinagem, vagamente, relataram esta utilização. Denota-se na fala dos entrevistados, ferramentas isoladas sem descrição:

"O desenvolvimento de competências, o portal, as orientações oferecidas" (E3).

"Orientações sobre o programa da disciplina e o plano de aula" (E15).

"Podemos verificar a carga horária da disciplina, tanto na teoria quanto na prática, o que muitas vezes fica pequeno para atender a disciplina (E1)".

"Para o docente, às vezes falta tempo para cumprir o recomendado no PPP" (E5).
"Neste momento é muito importante a percepção e atuação dos docentes no sentido de estarem na ponta observando a necessidade do curso e dos discentes" (E7).

Existe um fator de fundamental relevância quando abordado o Projeto Político Pedagógico, pois, mais da metade dos pesquisados não opinaram sobre assunto, ou afirmaram não participar ativamente do PPP do curso em que lecionam. Um dos maiores desafios para a educação da atualidade, diz respeito aos docentes, pois eles são o ponto de partida para o progresso. Além disso, as resistências às mudanças e a pouca interdisciplinaridade são alguns exemplos que necessitam de superação (JUSTO; BRITO, 2011).

Nesse contexto, para se efetivar o processo de construção e atualização do PPP, é fundamental que haja maior envolvimento docente e discente, pois apesar destes terem o conhecimento que o projeto norteia e qualifica a sua formação acadêmica, ainda demonstram passividade e desinteresse em participar (SILVA; FREITAS, 2010).

A trajetória do processo de ensinar requer profundas mudanças nas concepções pedagógicas dos professores. Exige do profissional não apenas um profundo conhecimento do conteúdo científico e pedagógico, mas também a interação entre os conteúdos das disciplinas de cunho específico com os das disciplinas pedagógicas. Para atender essa expectativa é fundamental o conhecimento e construção contínua do PPP, elemento norteador dos cursos de graduação (SILVA; CARVALHO, 2014).

O Projeto Político Pedagógico é de acesso a todos os docentes da instituição, porém, é utilizado por um número restrito. No entanto, para ocorrer as mudanças necessárias na prática pedagógica além de, verificar as relações entre o sentido do trabalho do docente, seus desafios diários, suas concepções sobre o processo de ensinagem e relacionamento com o discente, é necessário que o docente seja um sujeito transformador deste processo e, por conseguinte, participante ativo, no uso pleno da interdisciplinaridade, de uma reorganização nas estratégias de ensino

Entendendo o processo de ensinar como desafiador e, sobretudo, inovador no sentido de perpétua adaptação à realidade, sem contanto interferir nos conteúdos curriculares, epistemologicamente, deve-se levar em consideração as limitações e critérios de conhecimento dos sujeitos envolvidos nesta ação na tentativa de ampliar as possibilidades do movimento de ensinagem, enfatizando dificuldades docentes com o intuito de focar em estratégias que possam modificar atitudes e promover capacitações mais adequadas aos discentes desta aérea.

\section{CONCLUSÕES}

O contexto deste estudo pontua fatores positivos que interferem no processo de ensino da graduação, como aprimoramento e experiência profissional. Com relação as dificuldades encontradas, mostrou-se a falta de motivação dos discentes, a alta carga horária vivenciada pelos docentes bem como as tensões profissionais, escassez de 
tempo para o aprimoramento profissional e exigências do mercado de trabalho.

\section{REFERÊNCIAS BIBLIOGRÁFICAS}

ALBUQUERQUE, M. A. C.; AMORIM, A. H. C.; ROCHA, J. R. C. F.; SILVEIRA, L. M. F. G.; NERI, D. F. M. Bioquímica como Sinônimo de Ensino, Pesquisa e Extensão: um relato de experiência. Rev. Bras. de Educação Médica, v. 36, n. 1, p. 137 - 42, 2012.

ARABSHAHI, K. S.; HAGHANI, F.; BIGDELI, S.; OMID, A.; ADIBI, P. Challenges of the ward round teaching based on the experiences of medical clinical teachers. Journal of Research in Medical Sciences: The Official Journal of Isfahan University of Medical Sciences, v. 20, n. 3, p. 273-80, 2015.

ARAUJO, E. S. C.; VIEIRA, V. M. O. Prácticas docentes en la salud: contribuciones para una reflexión a partir de Carl Rogers. Psicol. Esc. Educ., Maringá, v. 17, n. 1, p. 97-104, 2013.

BACKES, V. M. S., MOYA, J. L. M.; PRADO, M. L.; MENEGAZ, J. C.; CUNHA, A. P.; FRANCISCO, B. S. Expressões do conhecimento didático do conteúdo de um professor experimentado de enfermagem. Texto contexto enferm., Florianópolis, v. 22, n. 3, p. 804-10, 2013.

BACKES, V. M. S.; MOYA, J. L. M.; PRADO, M. L. Processo de construção do conhecimento pedagógico do docente universitário de enfermagem. Rev. Latino-Am. Enfermagem, Ribeirão Preto, v. 19, n. 2, p. 421-28, 2011.

BARDIN, L. Análise de conteúdo. Ed. Rev. atual. Portugal: Edições 70, 2009.

BOLZAN, D. P. V.; ISAIA, S. M. A.; MACIEL, A. M. R. Formação de professores: a construção da docência e da atividade pedagógica na Educação Superior. Rev. Diálogo Educ., Curitiba, v. 13, n. 38, p. 49-68, 2013.

CONSELHO NACIONAL DE EDUCAÇÃO - CNE. Desafios e Perspectivas da Educação Superior Brasileira para a Próxima Década. Parecer CNE/CES N. ${ }^{\circ} 210$, de 8 de julho de 2004. Documento de Referência para Oficina de Trabalho CES/CNE, 2010. Disponível em: <http://portal.mec.gov.br/cne>. Acesso em: 03 out. 2015.

CONSELHO NACIONAL DE SAÚDE - CNS. Resolução $\mathrm{N}^{\mathrm{o}} 466$ de 12 de dezembro de 2012 - Regulamenta a Resolução No 196/96 acerca das Diretrizes e Normas Regulamentadoras de Pesquisas Envolvendo Seres Humanos. Brasília (DF): Ministério da Saúde; 2012. [citado 2014 mar 17]. Disponível em: <http://conselho.saude.gov.br/resolucoes/2012/Reso466.p df>. Acesso em: 28 set. 2015.

COSTA, S. M.; DURÃES, S. J. A.; ABREU, M. H. N. G. Feminização do curso de odontologia da Universidade Estadual de Montes Claros. Ciênc. Saúde Coletiva, Rio de Janeiro, v. 15, n. 1, p.1865-73, 2010.
COTTA, R. M. M.; SILVA, L. S.; LOPES, L. L.; GOMES, K. O.; COTTA, F. M.; LUGARINHO, R.; MITRE, S. M. Construção de portfólios coletivos em currículos tradicionais: uma proposta inovadora de ensinoaprendizagem. Ciênc. Saúde Coletiva, Rio de Janeiro, v. 17, n. 3, p. 787-96, 2012.

FREIRE, P. Pedagogia da autonomia: saberes necessários à prática educativa. 41. ed. São Paulo: Paz e Terra, 2010.

FREITAS, Z. L.; CARVALHO, L. M. O.; OLIVEIRA, E. R. Educação de professores da universidade no contexto de interação universidade-escola. Ciênc. educ. (Bauru), Bauru, v. 18, n. 2, p. 323-34, 2012.

JUSTO, M. C.; BRITO, R. L. G. L. Formação Continuada de Docentes do Ensino Superior: possibilidades de construção grupal de saberes de docentes em instituição particular de ensino. In: ENCONTRO DE PESQUISADORES DO PROGRAMA DE EDUCAÇÃO, 10, 2011, PUC, São Paulo, set., 2011.1 CD-ROM.

LEMOS M. C.; PASSOS, J. P. Satisfação e frustração no desempenho do trabalho docente em enfermagem. Reme Rev. Min. Enferm., v. 16, n. 1, p. 48-55, 2012.

MENDES, M. B.; SILVA, A. L.; LOURENÇO, A. M. G.; LIMA, G. A.; MEDEIROS, I. Z. N.; COELHO, L. F. O.; BARBOSA, R. C. A.; ARRUDA, V. C. M. Extensão universitária: entenda e estenda a importância dessa ideia. In: JORNADA DE ENSINO, PESQUISA E EXTENSÃO, 10, 2010.1 CD-ROM.

MINAYO , M. C. S. Importância da avaliação qualitativa combinada com outras modalidades de avaliação. Saúde \& Transformação Social, Florianópolis, v.1, n.3, p. 2-11, 2011.

MOURA, E. C. C.; MESQUITA, L. F. C. Estratégias de ensino-aprendizagem na percepção de graduandos de enfermagem. Revista Brasileira de Enfermagem, Brasília, v. 5 , n. 63 , p. $793-98,2010$.

OLIVEIRA, C. B.; GONZAGA, A. M. Professor pesquisador - educação científica: o estágio com pesquisa na formação de professores para os anos iniciais. Ciênc. educ. (Bauru), Bauru, v. 18, n. 3, p. 689-702, 2012.

PAZ, P. O.; KAISER, D. E. A busca pela formação especializada em enfermagem do trabalho por enfermeiros. Rev. Gaúcha Enferm., Porto Alegre, v. 32, n. 1, p. 23-30, 2011.

PIMENTA, S. G.; ANASTASIOU, L. G. C. Docência no Ensino Superior. São Paulo: Cortez, 2010.

ROCHA, N. H. N.; BEVILACQUA, P.D.; BARLETTO, M. Metodologias participativas e educação permanente na formação de agentes comunitários/as de saúde. Trab. educ. saúde, Rio de Janeiro, v. 13, n. 3, p. 597-615, dez. 2015 . Disponível em Http://www.scielo.br/scielo.php?script=sci_arttext\&pid=S 
1981-77462015000300597\&lng=pt\&nrm=iso>. acessos em 17 nov. 2015. .

SALEH, A. M.; SHABILA, N. P.; DABBAGH, A. A.; AL-TAWIL, N. G.; AL-HADITHI, T. S. A qualitative assessment of faculty perspectives of small group teaching experience in Iraq. BMC Medical Educacion, v.15, n. 19, p.1-13, 2015.

SILVA, A. L.; FREITAS, M. G. O ensino do cuidar na Graduação em Enfermagem sob a perspectiva da complexidade. Revista Escola de Enfermagem, São Paulo, v. 3, n. 44, p. 687-93, 2010.

SILVA, J. R. N.; CARVALHO, L. M. O. Aportes Teóricos e Metodológicos para a Constituição de um
Grupo de Planejamento Conjunto com Docentes da Licenciatura em física. Ens. Pesqui. Educ. Ciênc., Belo Horizonte, v. 16, n. 2, p. 85-106, 2014.

SOUTO, T. S.; BATISTA, S. H.; ALVES BATISTA, N. A educação interprofissional na formação em Psicologia: olhares de estudantes. Psicol. cienc. prof., Brasília, v. 34, n. 1, p. 32-45, 2014.

TEIXEIRA F. G.; SILVA, M. R. S.; MEDEIROS, G. L. Síndrome de Burnout - a interface entre o trabalho na área da educação e na enfermagem. Revista de Enfermagem Referência. III Série, n, 2, p.101-109, 2010. 